\title{
Social Communication and Intercultural Mediation in Decompartmentalizing Identity Groups in Socio-political Crisis Context in Cameroon
}

\author{
Colette Djadeu Nguemedyam, Estelle Kamga Modjo \\ Advanced School of Mass Communication, University of Yaoundé 2, Yaounde, Cameroon
}

Email address:

colette_djadeu@yahoo.fr (C. D. Nguemedyam), estellemodjo@yahoo.fr (E. K. Modjo)

To cite this article:

Colette Djadeu Nguemedyam, Estelle Kamga Modjo. Social Communication and Intercultural Mediation in Decompartmentalizing Identity Groups in Socio-political Crisis Context in Cameroon. Humanities and Social Sciences. Vol. 4, No. 3, 2021, pp. 96-101.

doi: $10.11648 /$ j.jpsir.20210403.14

Received: April 20,2021; Accepted: May 14, 2021; Published: August 27, 2021

\begin{abstract}
From the corporatist strike in the North-West and South-West regions in 2016, from which the "Anglophone crisis" arose, to the campaign and the presidential elections of 2018, the results of which were openly contested by one of the candidates, there is the ongoing question of living together routinely emerge in the Cameroonian public space. These events appear as triggers of identity folds, until then latent in the collective subconscious. Among other things, they fostered the propensity and confrontation of hate speech between Cameroonians claiming different territories and identities: anglophonefrancophone, tontinard-sardinard, bamiléké-beti. Faced with this, certain public institutions such as the Ministry of Youth and Civic Education and the National Commission for the Promotion of Bilingualism and Multiculturalism, are sending out messages calling for civility, patriotism and tolerance. This paper demonstrate that, despite the limited confidence of Cameroonians in their public institutions, the discourses of these organizations are positioned within the framework of the intercultural tensions observed, as the third party speeh, and contribute to initiating the decompartmentalization of community and identity, with a view to consolidating a true culture and national identity. The Methodology consists precisely in analyzing the messages disseminated by these institutions on their Facebook pages, as well as the comments of their followers.
\end{abstract}

Keywords: Social Communication, Identities, Intercultural Mediation

\section{Introduction}

On October 11, 2016, lawyers from the English-speaking regions of Cameroon made a protest march in Bamenda to denounce the marginalization of their linguistic specificity in legal texts, their main working tool ${ }^{1}$. This date, which marks the beginning of the so-called "Anglophone" crisis, has fostered the awakening of various demands among the populations of these regions. It was then that following the lawyers, on November 21, 2016, it was the turn of teachers from these same regions to challenge the deployment of French-speaking teachers in English-speaking schools [14]. Consequently, in public spaces, particularly digital ones, which promote the democratization of public speaking, in particular

1 https://www.aa.com.tr/fr/afrique/cameroun-crise-anglophone-les-principalesdates-d-une-insurrection-chronologie/992032 accessed the 23th of October 2019. on Facebook pages like "Cameroon is Cameroon", we have observed verbal clashes between "Francophone" Internet users against "Anglophones": this were the event that provoked the first identity and community partitioning which was manifesting by the creation of Facebook pages dedicated to the English-speaking cause "Amba revolution", "Free southerm Cameroon".

On September 22, 2018, the presidential election campaign was launched in Cameroon. Paul Biya from the CPDM (Cameroon people's democratic movement) and Maurice Kamto from the CRM (Cameroon renaissance Movement) are two of the candidates for these elections. In a context of conquering the electorate, supporters of each side were deployed on the ground to distinguish themselves from the others, attract the attention and gain the confidence of potential voters. It was in this environment that the concepts "Tontinard" and "Sardinard" emerged [9]. They designate respectively the 
supporters of the CRM with reference to the tontine, a practice often assimilated to the Bamileke people from which the candidate of the CRM comes, and those of the CPDM with reference to the practice of distributing cans of sardines at the end of their political meetings. These initially political groups quickly evolved over the course of the said campaign towards ethno-tribal partitions linked to the ethnic origins of the candidates concerned. We could then observe an assimilation of "Tontinard" to "Bamiléké" and of "Sardinard" to "Béti". The contesting of the results of these elections by the candidate of the CRM, contributed to exacerbate the tensions between these two communities, manifested among other things by verbal clashes, hateful and offensive speech in the public space

In the two cases presented above, social and political demands turned into rivalries between Cameroonians claiming specific identities or belonging to particular cultural communities [17]. In this environment of "intercultural conflict", we specifically question the strategies for creating the messages emitted by the State of Cameroon, through its institutions devoted to the subject, which are precisely the Ministry of Youth and Civic Education, and the National Commission for the Promotion of Bilingualism and Multiculturalism, to negotiate with its citizens from all sides, the return to citizenship [8] and the consolidation of a culture and a national identity for everyone. How are these messages positioned as third party speeches in the Cameroonian public space, to help bring the different parties to interact on subjects and issues of general interest?

To initiate an answer to these questions, we will analyze in turn the messages posted on the Facebook pages of these two institutions and the comments of their followers.

\section{Sensitization Against Hate Speeches: Between Social Communication and Intercultural Mediation}

In the present paper, the authors understand Social communication as the fourth element of the social marketing mix, the aim of which is to educate and raise public awareness of behaviors and attitudes considered favorable for its own interest, and for the general interest [7]. While intercultural mediation designates a branch of social cohesion mediation [15], the objective of which is to establish or reestablish links of sociability between people from different cultures.

In Cameroon, two specific public institutions are deployed in the process of promoting civic values of living together and patriotism: the Ministry of Youth and Civic Education (MINJEC) and the National Commission for the Promotion of Bilingualism and multiculturalism (CNPBM).

MINJEC, on its Facebook page entitled "MINJEC Civic Campaign" created in April 2016, disseminates messages aimed at sensitizing Cameroonian public opinion, and young people in particular, on civic attitudes to adopt, in the face of current social issues. The various messages that are the subject of our analysis here come from its 2019 citizen vacation operations and the 2019 school and academic year. The National Commission for the Promotion of Bilingualism and Multiculturalism, for its part, uses its Facebook page as a medium communication to disseminate, among other things, its messages to raise awareness among Cameroonians about living together and cultural diversity. The elements examined within the framework of this study come precisely from its awareness campaign implemented in August 2019, against the hate speeches.

The views of those institutions are to promote living together are part of the approaches of social communication and intercultural mediation.

A) The social communication approach: call for behavior change

The principle of social communication in the logic of social marketing [16] is to get the targets concerned to abandon a behavior A, to adopt a behavior B that is suggested to them [13].

The analysis of our corpus from this perspective shows that the discursive approach of the two institutions concerned here seems to be built on the basis of social manifestations which they consider to be problematic from the point of view of citizenship. In this case, against the publications propagated on the social networks and likely according to them, to stir up hatred between Cameroonians of different sides, it broadcasts respectively on July 12, August 10 and September 1, 2019 "I say no to hate speeches in the social networks "'" Ban the prejudices, the complexes that feed discord, Cameroon needs all of us "2" I say no to hate speeches within my establishment $" 3$. In the same sense, considering that these so-called hateful remarks emanate from the increasingly reinforced, marked and claimed partitions between the different ethnic groups of this national space, the slogan "I say no to tribalism", is associated with it. These slogans resonate as denouncing behaviors and attitudes deemed negative for the general interest. At the same time, they call for the renunciation of said behaviors. For this, they explicitly name the disputed attitudes and behaviors "hate speech in social networks", "tribalism", "prejudices", "complexes", with the probable aim of arousing in Cameroonians an awareness of their potential consequences. "Feed the discord" and a questioning of their practices on this subject.

Moreover, alongside these calls for awareness and questioning, these institutions seem to want to offer Cameroonians conduct to take that they consider constructive and positive for national unity. The slogans "I join with other young people to promote and strengthen our living together",

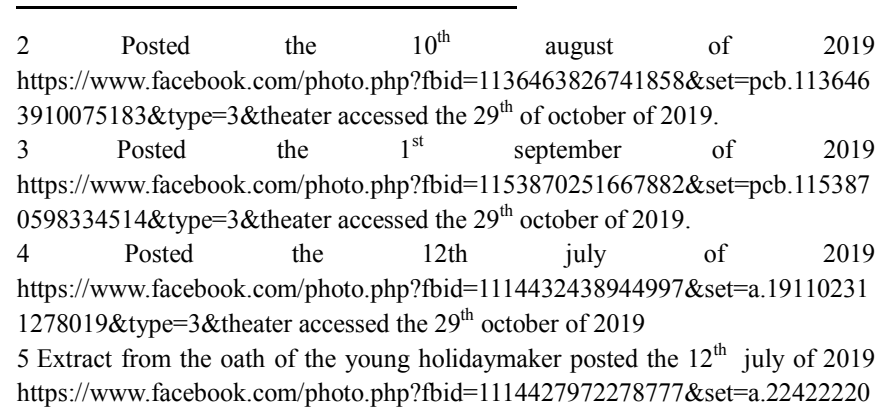


"I pledge to respect republican institutions" 6 "Cameroon needs all of us, serve our homeland"7 "Let's work together for a Cameroon in peace " 8 are the good illustrations of this desire and offers what social marketing experts call the tangible product, the proposed behavior ready to be implemented. The lexical field used here is more positivist and unifying. The use of the expressions "I associate myself", "live together", "I commit myself", "public institutions", "serve our homeland" connotes an ambition to create or strengthen in the Cameroonian collective imagination, the system of values built around the principles of patriotism and national unity.

B) The intercultural mediation approach: proposal of a "national culture"

The principle of intercultural mediation is the intervention of an intercultural mediator [6]. whose mission is to change the representations that some have of others, in order to build a space for communication and mutual understanding, which specialists in this field domain call "a third culture" [10].

This principle applies to the third type of argument that emerges from the messages issued by MINJEC and CNPBM a part of their awareness-raising activities: the construction or consolidation of a culture or national identity. The slogans "Peace is our most precious asset, let's preserve it", "We are one, we are cameroonians" ${ }^{10}$ " "Each ethnic group has its place within the Nation; it is the leaven of our unity "11," Cameroon needs all of us "12," Happiness is not the fruit of peace, happiness is peace itself "13," The cultural diversity of Cameroon is an asset for our development "14, translate this project well. The use of expressions such as "peace", "we are

7966029\&type $=3 \&$ theater accessed the 29th of october of 2019

6 accessed the $1^{\text {st }}$ september of 2019 https://www.facebook.com/photo.php?fbid=1153870251667882\&set=pcb.115387 $0598334514 \&$ type $=3 \&$ theater accessed the $29^{\text {th }}$ october of 2019

7 Posted the 21th july of 2019

https://www.facebook.com/photo.php?fbid=1121488074906100\&set=a.19110231

$1278019 \&$ type $=3 \&$ theater

accessed the $29^{\text {th }}$ october of 2019

8

https://www.facebook.com/cnpbmcameroun/photos/a.184121998834119/4720537 $90040937 /$ type $=3 \&$ theater accessed the $29^{\text {th }}$ october of 2019

9 Posted the 16th july of

2019https://www.facebook.com/photo.php?fbid=1117626805292227\&set=a.1911

02311278019\&type $=3 \&$ theater accessed the $29^{\text {th }}$ october of 2019

10 Posted the $19^{\text {th }}$ july of 2019

https://www.facebook.com/photo.php?fbid=1119964941725080\&set=a.19110231

$1278019 \&$ type $=3 \&$ theater accessed the $29^{\text {th }}$ october of 2019

11 Posted the $26^{\text {th }}$ july of 2019

https://www.facebook.com/photo.php?fbid=1125246574530250\&set=a.19110231 $1278019 \&$ type $=3 \&$ theater

accessed the $29^{\text {th }}$ october of 2019

12 Posted the $10^{\text {th }}$ august of 2019 https://www.facebook.com/photo.php?fbid=1136463826741858\&set=pcb. 113646 $3910075183 \&$ type $=3 \&$ theater accessed the $29^{\text {th }}$ october of 2019

13 Posted the $19^{\text {th }}$ of September of 2019 https://www.facebook.com/photo.php?fbid=1168803356841238\&set=pcb. 116880 $3430174564 \&$ type $=3 \&$ theater accessed the $29^{\text {th }}$ october of 2019

14 Posted the $18^{\text {th }}$ august of 2019 https://www.facebook.com/cnpbmcameroun/photos/a.184121998834119/4702786 $60218450 /$ ?type $=3 \&$ theater accessed the $29^{\text {th }}$ october of 2019 cameroonians", "Our unity", "all of us", "cultural diversity is an asset", evoke a desire to federate the various compartmentalised groups on the common project. That is the national development of Cameroon in unity, despite the differences, and in peace. Alongside awareness, questioning, and recommendations for behavior to adopt, these arguments are part of a visionary approach [1], in the sense that they propose to divided Cameroonians, the vision of a united Cameroon, around values that claim to be national and a common culture, which could be considered as "third culture" [15]. In this logic precisely, we can notice a form of centralization of the "legitimate mediator" [5]., represented here by the MINJEC and the CNPBM, which, according to the principle of neutrality [3]., disregards the details of the claims on both sides. It is limited to the proposal of a common vision [2]. To be shared by the parties in conflict, without however having their antagonistic interests dialogue beforehand [4]. A crucial element which, according to Chaouite Abdellatif, could constitute a factor of failure of the intercultural mediation process.

\section{Public Opinion in the Face of Sensitization: Between Adherence and Contestation}

It should be noted a priori that the comments of Internet users analyzed here are mainly those collected following messages disseminated by the CNPBM, because there are hardly any comments to those issued by MINJEC. A total of 54 comments were identified. Our analysis is intended to be qualitative. It consists in identifying the different postures of Internet users vis-à-vis awareness messages, this from their various comments.

In this logic, we have identified 3 main types of postures of Cameroonian Internet users: members, skeptics and protesters. While some seem to adhere to the messages and behaviors offered to them, others express either skepticism or questioning of the proposed mediation process.

A) Adherence to behaviors whose feasibility remains to be built

By adhering to the discourse of living together promoted, we mean those who, by comments such as "Amen", "very true", "the title is very clear", "we want peace, not tribalism", "top", "Finally!", "It is now that you leave your reserve to decry hateful and tribal speeches, it is never too late "," God bless you abundantly", "red card to the ethno-fascists and the prophets of the division", "courage"... seem to be identified with the arguments or behaviors promoted in this direction by the institutions concerned. It is also those who, even with reservations expressed in terms like: "Insofar as tribalism and favoritism are eradicated", "Unfortunately, this diversity has become a diversion, We still have some way", "If only deeds followed words?», Show their attachment to the values and principles that are proposed.

Following the logic of McGuire's sequential persuasion model [18], the messages sent would have reached with this 
first group of Internet users the fourth stage, which is that of acceptance, after exposure, attention and understanding. To believe their comments, the message of call to live together to which they are exposed, namely: "to work together for a Cameroon in peace" attracts their attention and seems to them comprehensive and acceptable, on condition for some, of a development. Structure and an effective commitment of the public authorities to take effective institutional and legal measures, likely to support the feasibility of the discourse promoted. In other words, in the logic of accessibility in social mix-marketing [7], the sensitization of Cameroonians to invest individually in the decompartmentalization of identity groups, requires available to them the frameworks and procedures for the feasibility of the behavior promoted, so that they can easily take action. This is to say that, for "reserved members" 15 , the current social, legal, administrative and political reality would not favor the practice of behaviors in favor of opening up to each other, established identity groups. If there are operational measures to promote this, the messages delivered by the institutions should mention them. The slogans would then go beyond the ideology of living together for peace, to be part of the demonstration of the procedures or practical steps of its operationalization by the Cameroonians. They would then answer the questions: "how to do?" "Or" what to do?" On a daily basis to contribute to living together for peace?

B) Contestation of the mediation logic deployed

The second category of posture of Internet users vis-à-vis institutional messages promoting living together in Cameroon is made up of skeptics of institutions, and protesters of the logic of mediation used by the latter to try to bring back problems. Cameroonians of different groups with common values for the national interest.

For the skeptics of institutions, we can read comments such as: "the kingdom of the paranormal", "you haven't seen anything yet" "This commission is null and void" "This commission eats billions every year for nothing", "And Comment???» «Stop confusing us with empty slogans» «Very false» «Nothing is expected of you anymore », «Damn! What hypocrisy!!", "Of your step of our heinn" "What have you done with it in the last 37 years of unchallenged reign? "If only the commissions were used for something.", "We make peace so that the thieves of the republic eat in peace?", "Hmmm the example must come from above the result of Enam and another is the illustration", "Personally I don't care", "band of sorcerer noughts and crosses", "Those who do it is because they are protected and therefore untouchable", "Our own leaders say one thing during the day and do the opposite at night." These comments translate in sometimes offensive and vulgar language, a crisis of confidence for the institutions carrying messages of appeasement and reconciliation. For the authors, the latter would be accomplices, even actors, in the socio-political realities which generate ideological, ethnic and cultural segregations. With reference to the work of the Yale School [7], these

15 Those who accept the message with reserve. would therefore not be credible as emitting sources with which they could identify in the efforts to be made for the adoption of the behaviors promoted. From the perspective of intercultural mediation, this also expresses a challenge to those who position themselves as intercultural mediators by one of the parties to the confli ct [5], a situation which would guarantee, according to the experts, an a priori failure of the mediation process.

Besides the mediator, it is also the process and the relevance of the intercultural mediation process that seem to be called into question by Internet users. They make various comments that can be seen as a reconsideration of the arguments disseminated and the actions deployed with a view to appeasement: "how can a government make us believe that it is promoting bilingualism and multiculturalism by leaving its citizens send hateful and tribal missiles all day long on the web, radio and TV channels and this with complete impunity?", "No to the abusive arrests of political prisoners" and others which resonate as proposals for questions to evoke the framework of the exchanges between the mediators and the parties: "introduce a law against tribalism", "clean up the constitution", "The big problem is not the language problem, but not listening to the cry of distress of the people in the face of the difficulties, not really considering the people's problems, and let's eat it together", "the problem is inequality sharing our resources", "let's eat together and peace will follow", "No to the misappropriation of public funds, yes to inclusive dialogue in the Noso regions, yes to eating together". From the perspective of intercultural mediation, this is a call to those whom we consider in this context as mediators, to refocus in order to raise in their speeches, questions that the parties in conflict consider to be the real knots of discord. Mediation action cannot be deployed on the basis of a conflict whose causes are ignored or bypassed. All the more so when the so-called mediator is assimilated by one of the parties to the conflict, as an adjunct to his adversary.

At the same time, these anger and sketches of proposals from Internet users of different groups, denote what they find in these spaces created by the institutions concerned, a framework favorable to the expression and construction of new ideas in the perspective of 'a more peaceful common future.

\section{Partitioned Identity Groups for Constructive Exchanges for the National Interest}

The institutional Facebook pages of MINJEC and CNPBM promote the opening of certain Internet users who were initially members of Facebook communities compartmentalized in their ethnic or ideological affiliations, to a more global community in which the main stake is the national interest. In this virtual community, speeches calling for tolerance and living together are broadcast that constitute the pretext for reactions and comments. Through the 
possibilities of reactions and comments that they offer to Internet users, Facebook institutional pages fulfill the cathartic function. It encourages the punctuation of the communication as recommended by Paul Watzslavick in the context of the success of a communication in conflict situation.

A) The cathartic function of institutional awareness publications

The awareness messages disseminated on the institutional Facebook pages of MINJEC and CNPBM give to Cameroonians the opportunity to react and comment. As a result, they allow angry Internet users to express their frustrations at times violently and fiercely, by letting off steam on the institutions they consider responsible for their misfortune. Once feelings and passion are exteriorized, they are in principle more willing to engage in more constructive exchanges of ideas with members of opposing groups.

B) Facebook posts as a favorable factor for punctuation of communication

In his pragmatic model of communication, Paul Watzlavick mentions among the five postulates of successful communication the punctuation of the communication sequences between partners as factors determining the nature of their relationship.

The Facebook publications of the institutions mentioned encourage this punctuation insofar as, although they encourage the confrontation of the contradictory ideas and demands of Internet users, they also allow the latter, from identity groups in conflict, to take the time to read each other, to meditate on each other's comments and even to put themselves in each other's shoes. This favors the evolution of reciprocal representations and helps to start the decompartmentalization of communities.

\section{Conclusion}

From a reading of social communication [7], and intercultural [8], this article demonstrate that, in the Cameroonian socio-political context characterized by intercultural tensions, the discourses of public institutions position themselves as third-party discourse, and contribute to initiating the decompartmentalization of community and identity, with a view to consolidating a true culture and national identity. The analysis of the creative strategies of the messages emitted by these public institutions to negotiate with its citizens on the return to citizenship and peaceful living together, has enabled us to decipher a combined approach of persuasion to change behavior in 4 stages, and of construction of a national culture as a third culture between the groups in conflict. Alongside these institutional discourses, the analysis of Internet users' comments revealed to us, for some, an adherence to the values promoted tinged with reservations about the feasibility of the suggested behaviors, and for others a challenge to the issuing public institutions in the process of intercultural mediation and even the logic of mediation adopted. Despite these reservations and disputes, the messages disseminated in the democratized communication spaces offered by the institutional Facebook pages concerned, promote discussion by members of the different groups who are separated or in conflict. On this discussion ground, the framework defined revolves around living together, unity in diversity and the conditions of their feasibility. This framework arouses an externalization of negative feelings and passions against one another or against the issuer itself and helps to provoke constructive exchanges in a perspective of general interest.

To consider moving closer to the ideal of peaceful living together in the diversity that the MINJEC and the CNPBM seem to advocate, this process would probably be reinforced with the improvement of the strategy of animation of the dedicated Facebook pages, in addition to taking into consideration, as far as possible, the relevant claims and proposals of Cameroonian Internet users in the area of social justice.

\section{References}

[1] Allali, B. (2007). Pour des réseaux de P. M. E. clarifiants: une approche visionnaire. Gestion, vol. 32 (2), 81-90. doi: 10.3917/riges.322.0081.

[2] Ben Mrad, F. (2004). «La médiation sociale: entre résolution de conflit et sécurisation urbaine», Revue française des affaires sociales, $\mathrm{n}^{\circ} 3$, p. 231-248.

[3] Bernard, N. (2007). «Formation à la médiation: un contenu spécifique et une analyse des pratiques», Non-Violence actualité, $n^{\circ} 293$, p. 9-10.

[4] Chaouite, A (2004). Risques et spécificités de la médiation interculturelle. In: Hommes et Migrations, $n^{\circ} 1249$, Mai-juin 2004. Médiations et travail social. pp. 77-86; doi: https://doi.org/10.3406/homig.2004.4181https://www.persee.f r/doc/homig_1142-852x_2004_num_1249_1_4181.

[5] Cohen-Emerique, M. (2004). «Positionnement et compétences spécifiques des médiateurs», Hommes et migrations, $\mathrm{n}^{\circ} 1249$, p. $36-52$.

[6] Cohen-Emerique, M. Fayman, S. (2005). «Médiateurs interculturels, passerelles d'identité», connexions, $\mathrm{n}^{\circ} 83$ (1), p. 169-190.

[7] Cosette, C. et Pénélope, D. Publicité sociale, définition, particularité et usage, telemaque.org Québec, 2011 https://issuu.com/com.ulaval.ca/docs/interieurtome1hd.

[8] Elhajji, M. et Arapu, D. (2007), Communication Interculturelle Et Nouvelles Formes De Négociation De La Citoyenneté, Presses Universitaires de France | «Diogène» 2007/4 n 220 pages 110 à $117 \mathrm{https}$ ://www.cairn.inforevuediogene-2007-4-page-110.htm/.

[9] Mbetbo Félix (2021) Dialogue entre un sardinard et un tontinard: savoir-vivre ou mourir-ensemble, les éditions du Muntu ISBN 10: 2492170020.

[10] Gaillard, B.; Durif-Varembont, J.-P. (2007). La médiation, théorie et pratique, Paris, L'Harmattan.

[11] Gordon, R (2011) «Critical social marketing: definition, application and domain», J Social Marketing, 1, 2, 82-99. 
[12] Hastings, G. Saren, M. (2011). «The critical contribution of social marketing: theory and application», Marketing Theory, 3 (3), 305-322, 2003.

[13] Kotler, P. Lee, N. (2008) Social Marketing: Influencing behaviours for Good, Sage Publications, $3^{\text {rd }}$ ed.

[14] Machikou, N. (2018). Utopie et dystopie ambazoniennes: Dieu, les dieux et la crise anglophone au Cameroun. Politique africaine, $\quad 2$ (2), 115-138 https://doi.org/10.3917/polaf.150.0115.

[15] Plivard, I. (2010). La pratique de la médiation interculturelle $\mathrm{au}$ regard des populations migrantes. et issues de l'immigration. Connexions, 93 (1), 23-38. doi: 10.3917/cnx.093.0023.

[16] Smith, W. A (2006). Social marketing: an overview of approach and effects, injury prevention. Jun; 12 (Suppl 1): i38-i43. doi: 10.1136/ip.2006.012864.

[17] Vinsonneau, G. (2002). L'identité culturelle, Paris, Armand Colin.

[18] Watts, W. A., \& McGuire, W. J. (1964). Persistence of induced opinion change and retention of the inducing message contents. The Journal of Abnormal and Social Psychology, 68 (3), 233-241. http://dx.doi.org/10.1037/h0041081. 